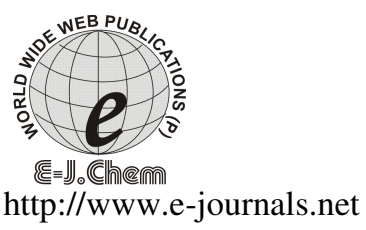

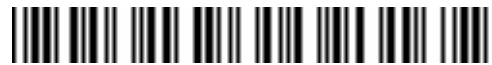 \\ ISSN: 0973-4945; CODEN ECJHAO \\ E-Journal of Chemistry
}

Vol. 4, No.1, pp 79-82, January 2007

\section{Spectrophotometric Determination of Raloxifene Hydrochloride in Pharmaceutical Formulations}

\author{
M. MATHRUSRI ANNAPURNA*, M. E. BHANOJI RAO \\ and B.V.V.RAVI KUMAR \\ Department of Pharmaceutical Chemistry, \\ Roland Institute of Pharmaceutical Sciences, \\ Ambapua, Berhampur, Orissa-760010. \\ mathrusri2000@yahoo.com
}

Received 6 September 2006; Accepted 15 October 2006

\begin{abstract}
Three new simple, sensitive, rapid and economical spectrophotometric Methods (A, B and C) have been developed for the determination of Raloxifene Hydrochloride in pharmaceutical bulk and tablet dosage form. Method A is based on the formation of yellow colored chromogen with $0.1 \mathrm{~N}$ Sodium hydroxide exhibiting maximum absorbance against the corresponding reagent blank. The method B is based on the reaction of Raloxifene with Ferric chloride and 1, 10-phenanthroline to form blood red colored chromogen. The method $\mathrm{C}$ is based on the formation of blood red colored chromogen with Ferric chloride and 2, 2' bipyridyl. The absorbencies of the chromogens were measured at their respective wavelength of maximum absorbance against the corresponding reagent blank. The proposed methods have been successfully applied to the analysis of the bulk drug and its tablet dosage form. The methods have been statistically evaluated and were found to be precise and accurate.
\end{abstract}

Keywords: Raloxifene Hydrochloride, 1, 10-phenanthroline, Sodium hydroxide, 2, 2' bipyridyl.

\section{Introduction}

Raloxifene Hydrochloride ${ }^{1}$ is a new anti-osteoporotic agent, with a chemical name 6-Hydroxy-2(4-hydroxy phenyl) benzo \{b\} thien-3-yl] [4-\{2-(1-piperidinyl)-ethoxy\}-phenyl] methanone. Clinically it is effective in the treatment of breast cancer ${ }^{2,3}$ and in reduction of fracture risk $^{4}$. It is an estrogenagonist in bone, where it exerts an anti-resorptive effect. The results of several large clinical trials have shown that raloxifene reduces the rate of bone loss 
at both distal sites and in the spinal column and may increase bone mass at certain sites ${ }^{5}$. There are very few methods described in the literature for the determination of Raloxifene. All of them use high-performance liquid chromatography (HPLC). The drug has been determined in human plasma using the LC/MS/MS technique ${ }^{6}$. Reverse phase HPLC with UV detection has been proposed for quantifying Raloxifene hydrochloride $\mathrm{e}^{7-9}$. In the present investigation, the authors have developed three simple and sensitive spectrophotometric methods for the determination of Raloxifene hydrochloride.

\section{Experimental}

\section{Instrument}

Elico UV Visible spectrophotometer SL 159 with $1 \mathrm{~cm}$ matched quartz cells was used for all spectral measurements.

\section{Reagents}

All the reagents used were of analytical reagent grade. All the solutions were freshly prepared. For Method A, aqueous solution of sodium hydroxide $(0.1 \mathrm{M})$ was prepared. The reagents used in Method B were Ferric chloride $(0.03 \mathrm{M})$ and 1,10 -phenanthroline $(0.01 \mathrm{M})$ and in Method $\mathrm{C}$ were Ferric chloride $(0.03 \mathrm{M})$ and 2,2 bipyridyl $(0.01 \mathrm{M})$.

\section{Procedure}

Standard stock solution:

A standard stock solution containing $1 \mathrm{mg} / \mathrm{ml}$ was prepared by dissolving accurately $100 \mathrm{mg}$ of Raloxifene Hydrochloride in $100 \mathrm{ml}$ methanol. From this, a working standard solution containing $100 \mu \mathrm{g} / \mathrm{ml}$ was prepared for Method A, B and C with methanol.

\section{Method A}

Aliquots of standard solutions containing $0.5-1.5 \mathrm{ml}$ of $100 \mu \mathrm{g} / \mathrm{ml}$ and $1 \mathrm{mg} / \mathrm{ml}$ were transferred into a series of $10 \mathrm{ml}$ graduated test tubes separately and the total volume was made up to $10 \mathrm{ml}$ with $0.1 \mathrm{M}$ sodium hydroxide. The absorbance of the yellow colored chromogen was measured at $425 \mathrm{~nm}$ against reagent blank. The amount of Raloxifene Hydrochloride present in the sample solution was computed from its calibration curve.

\section{Method B}

In to a series of $10 \mathrm{ml}$ graduated test tubes, $0.1-1.0 \mathrm{ml}(1 \mathrm{ml}=100 \mu \mathrm{g} / \mathrm{ml})$ of working standard solution was pipetted separately and $1 \mathrm{ml}$ of $0.03 \mathrm{M}$ ferric chloride solution and 1.5 $\mathrm{ml}$ of $0.01 \mathrm{M} \mathrm{1,10-phenanthroline} \mathrm{was} \mathrm{added.} \mathrm{The} \mathrm{test} \mathrm{tubes} \mathrm{were} \mathrm{then} \mathrm{heated} \mathrm{on} \mathrm{water} \mathrm{bath}$ for 15 minutes at $60^{\circ} \mathrm{C}$, cooled to room temperature and the total volume was made up to 10 $\mathrm{ml}$ with double distilled water. The absorbance of the blood red colored species was measured at $510 \mathrm{~nm}$ against reagent blank. The amount of Raloxifene Hydrochloride present in the sample solution was computed from its calibration curve.

\section{Method C}

In to a series of $10 \mathrm{ml}$ graduated test tubes, $0.2-2.5 \mathrm{ml}(1 \mathrm{ml}=100 \mu \mathrm{g} / \mathrm{ml})$ of working standard solution was pipetted separately and to each test tube $1 \mathrm{ml}$ of $0.03 \mathrm{M}$ ferric chloride solution and $1.5 \mathrm{ml}$ of $0.01 \mathrm{M} \mathrm{2}$, 2' bipyridyl were added and kept aside for five minutes and the total volume was made up to $10 \mathrm{ml}$ with double distilled water. The absorbance of the blood red colored chromogen was measured at $521 \mathrm{~nm}$ against reagent blank. The amount of drug in the sample was computed from Beer-Lambert plot. 


\section{Preparation of sample solution}

Tablets containing Raloxifene Hydrochloride were successfully analyzed by the proposed methods. Twenty tablets of commercial samples of Raloxifene Hydrochloride were accurately weighed and powdered. Tablet powder equivalent to $100 \mathrm{mg}$ of Raloxifene was dissolved in $50 \mathrm{ml}$ methanol and filtered and washed with methanol, the filtrate and washings were combined and the final volume was made up to $100 \mathrm{ml}$ with methanol. The solution was suitably diluted and analyzed as given under the assay procedure for bulk samples. The results were represented in Table 1 . None of the excipients usually employed in the formulation of tablets interfered in the analysis of Raloxifene Hydrochloride by the proposed methods.

\section{Recovery studies}

To ensure the accuracy and reproducibility of the results obtained, recovery experiments were performed by adding known amounts of pure drug to the previously analyzed formulated samples and these samples were reanalyzed by the proposed method. The percentage recoveries thus obtained were given in Table 1.

Table 1. Assay of raloxifene hydrochloride

\begin{tabular}{cccccccc}
\hline \multirow{2}{*}{$\begin{array}{c}\text { Sample } \\
\text { (Tablet) }\end{array}$} & $\begin{array}{c}\text { Labeled } \\
\text { Amount } \\
\text { mg }\end{array}$ & \multicolumn{3}{c}{$\begin{array}{c}\text { Amount obtained } \\
\text { mg* }\end{array}$} & \multicolumn{3}{c}{$\begin{array}{c}\text { **\% Recovery by the } \\
\text { proposed method }\end{array}$} \\
\cline { 3 - 8 } & & $\begin{array}{c}\text { Method } \\
\text { A }\end{array}$ & $\begin{array}{c}\text { Method } \\
\text { B }\end{array}$ & $\begin{array}{c}\text { Method } \\
\text { C }\end{array}$ & $\begin{array}{c}\text { Method } \\
\text { A }\end{array}$ & $\begin{array}{c}\text { Method } \\
\text { B }\end{array}$ & $\begin{array}{c}\text { Method } \\
\text { C }\end{array}$ \\
\hline 1 & 60 & 59.16 & 59.95 & 59.71 & 98.59 & 99.92 & 99.52 \\
2 & 60 & 59.83 & 59.86 & 59.85 & 99.72 & 99.76 & 99.76 \\
\hline
\end{tabular}

*Average of three determinations.

**After spiking the sample

\section{Results and Discussion}

The optimum conditions were established by varying on parameter at a time and keeping the others fixed and observing the effect on absorbance. The effect of temperature of the reaction, quantity, concentration and addition of various reagents were studied, optimized after several experiments and incorporated in the procedure. The yellow color developed sodium hydroxide in Method A was stable for more than 48 hours and in case of Method B and Method $\mathrm{C}$ the color was stable for 2 hours only. The reaction involved in Method B and Method C may be due to the fact that the unshared pair of electrons on each of the two nitrogen atoms of 1, 10-phenanthroline as well as 2, 2' bipyridyl complexes with $\mathrm{Fe}^{2+}$ ion formed by the reaction between Raloxifene and $\mathrm{Fe}^{3+}$ ion.

The optical characteristics such as absorption maxima, Beer's law limits, molar absorptivity and Sandell's sensitivity are presented in Table 2 . The regression analysis using the method of least squares was made for slope (m), intercept (c) and correlation obtained from different concentrations and the results are summarized in Table 2. 
Table 2. Optical characteristics of the proposed methods

\begin{tabular}{llll}
\hline Parameters & Method A & Method B & Method C \\
\hline$\lambda_{\max }($ nanometers $)$ & 425 & 510 & 521 \\
Beer's law limits $(\mu \mathrm{g} / \mathrm{ml})$ & $5-150$ & $1-10$ & $2-25$ \\
Molar extinction coefficient & $3.621 \times 10^{3}$ & $6.314 \times 10^{4}$ & $2.101 \times 10^{4}$ \\
$\left(1 \mathrm{mo}^{-1} \mathrm{~cm}^{-1}\right)$ & & & \\
Sandell's sensitivity & 0.1408 & 0.0081 & 0.0243 \\
$\left(\mu \mathrm{g} / \mathrm{cm}^{2} / 0.001\right.$ absorbance Unit) & & & \\
Regression equation $*(\mathrm{Y})$ & & & \\
Slope (m) & 0.0070 & 0.1239 & 0.0412 \\
Intercept (c) & 0.0024 & 0.0004 & 0.0007 \\
Correlation coefficient $(\mathrm{r})$ & 0.9999 & 0.9999 & 0.9999 \\
\hline
\end{tabular}

$* \mathrm{Y}=\mathrm{m} \mathrm{X}+\mathrm{c}$, where $\mathrm{X}$ is the concentration in $\mu \mathrm{g} / \mathrm{ml}$ and $\mathrm{Y}$ is absorbance unit.

\section{Conclusions}

The proposed methods are economical, simple and sensitive for the determination of RLX in any pharmaceutical preparations and did not suffer from any interference due to common excipients of tablets like talc, starch, magnesium stearate and lactose.

\section{Acknowledgements}

Authors are grateful to M/S BAL Pharma, India for supplying the gift sample and to M/S Roland institute of pharmaceutical sciences, Berhampur, Orissa, India-760010 for providing the necessary research facilities.

\section{References}

1. Ann Smith, Patrica E Heckelman, John R Obenchain, Jo Ann R Gallipeau, Mary Ann D' Arecca, Susan Budavari, The Merck Index, $13^{\text {th }}$ Edition, Merck Research Laboratories, Division of Merck and Co., Inc; White house station, NJ, 2001, 1452.

2. Cummings S R, J. Am. Med. Assoc., 1997, 281, 2189.

3. Hol T, Cox M B, Bryant H U and Draper M W J, Womens Health 1997, 6, 523.

4. $\quad$ Ettinger B ibid., 1999, 282, 637.

5. Delmas P, Bjarnason N H, Mitlak B H, Ravoux A C, Shah A S, Huster W J, Draper A and Christiansen C N, Engl. J. Med. 1997, 337, 1641.

6. Zweigenbaum J and Henion J, Anal. Chem. 2000, 72, 2446.

7. Nandini P and Jayant W P, Indian Drugs, 2001, 38, 591.

8. Wang Q, Zhang H M, Yu Z G and Shenyang Yaoke Daxue Xuebao, 2002, 19, 105.

9. Venkata Reddy P, Sudha Rani B, Srinubabu G and Seshagiri Rao J V L N, E- J. Chem. 2006, 3(10), 60 . 


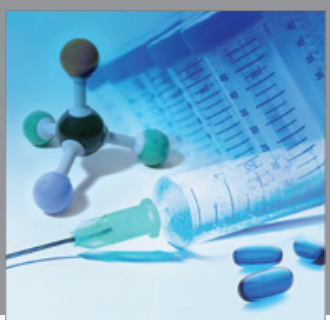

International Journal of

Medicinal Chemistry

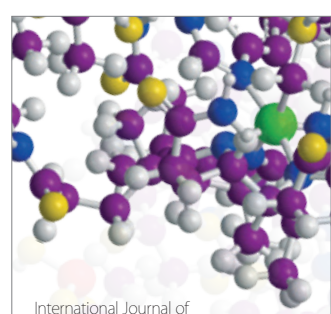

Carbohydrate Chemistry

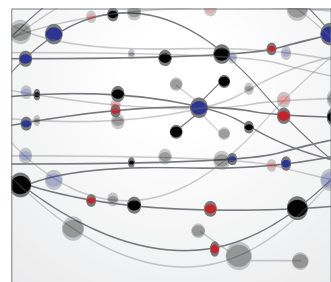

The Scientific World Journal
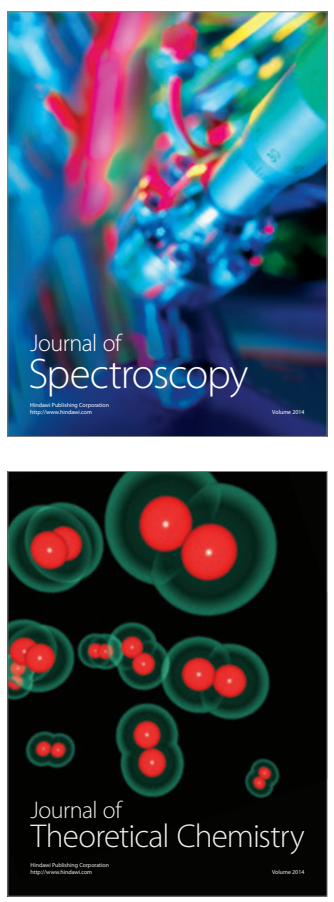
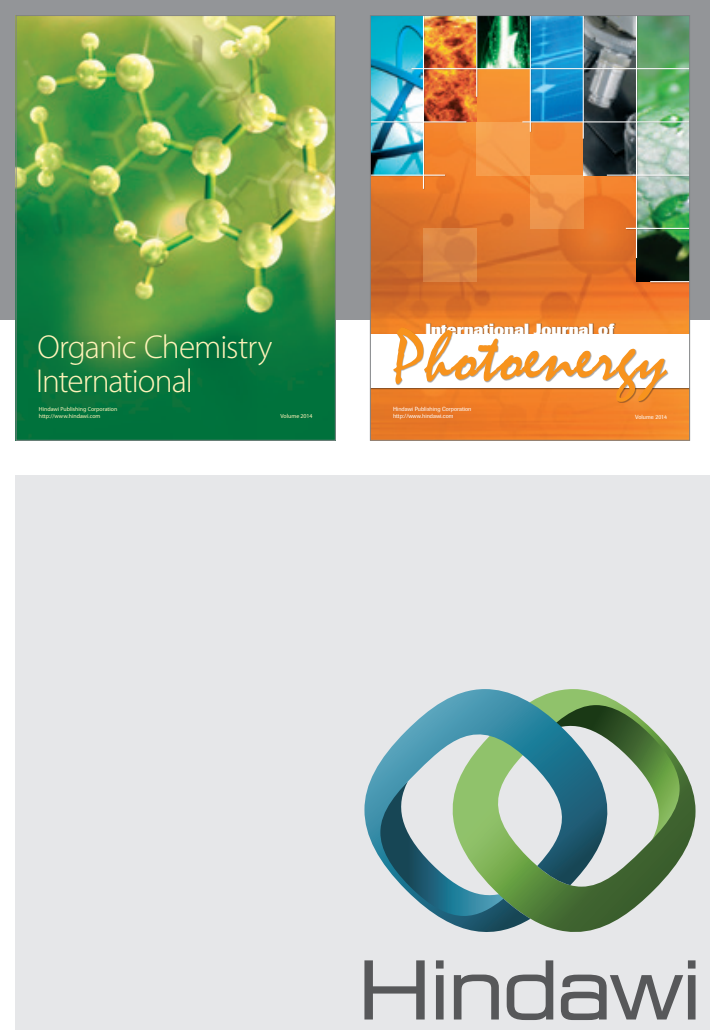

Submit your manuscripts at

http://www.hindawi.com
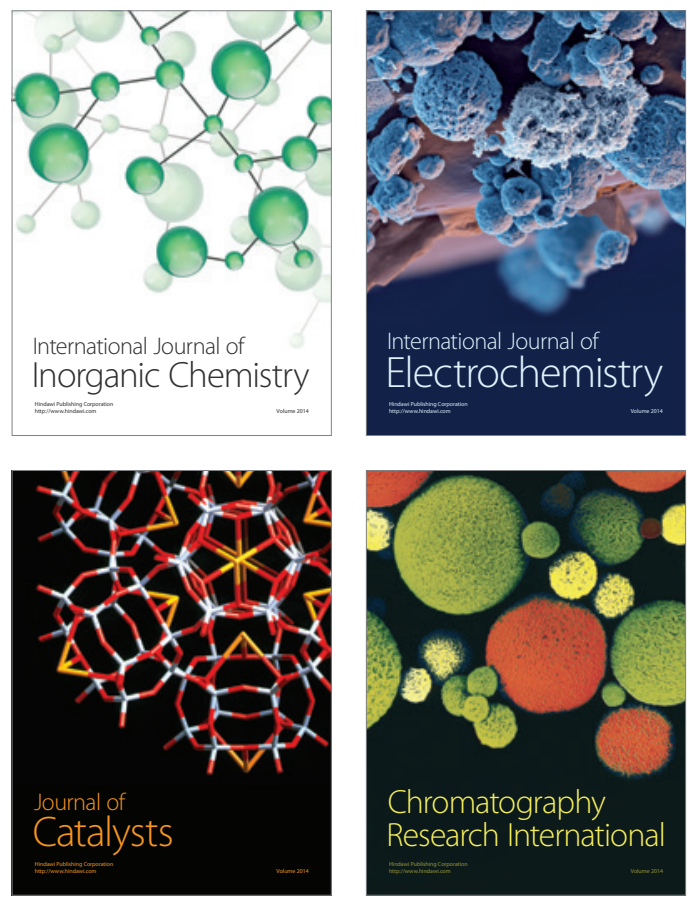
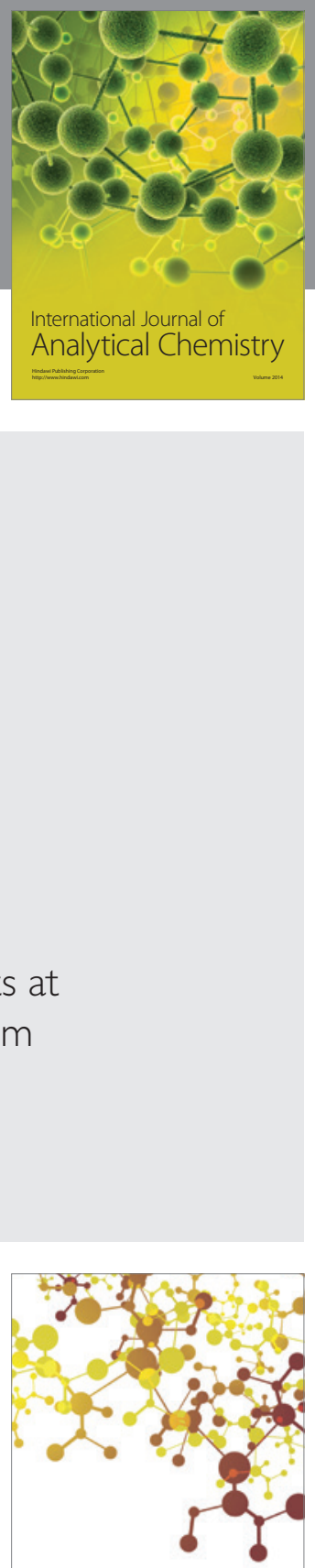

Journal of

Applied Chemistry
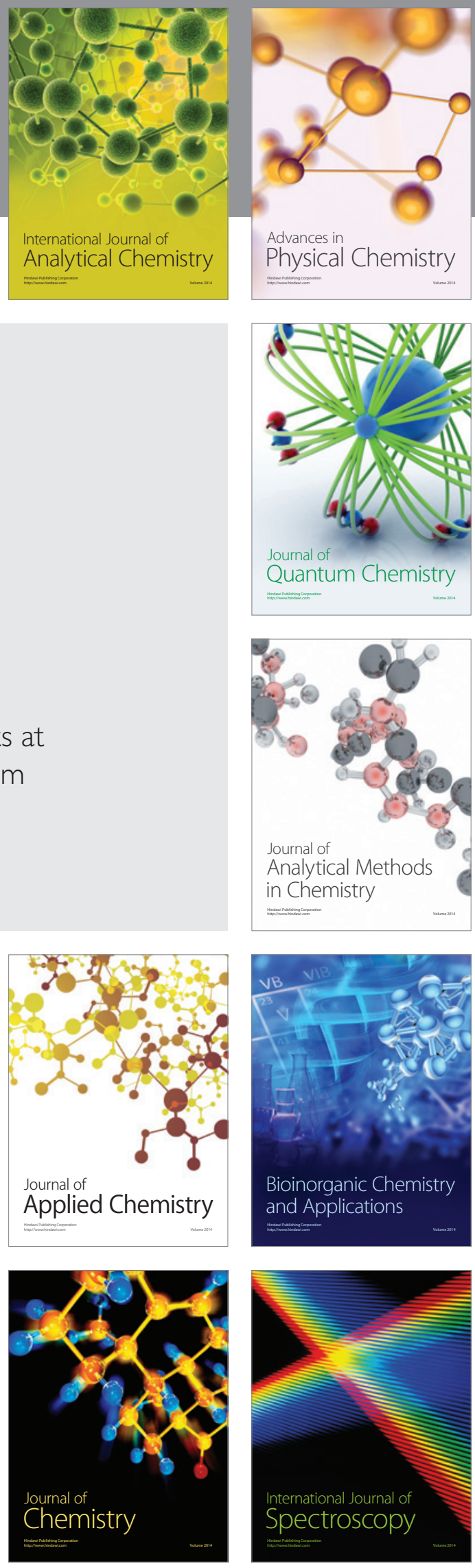